\title{
CHANGES IN CALCIUM OXALATE CRYSTAL MORPHOLOGY AS A FUNCTION OF SUPERSATURATION
}

\author{
MAURICIO CARVALHO, MARCOS A. VIEIRA \\ Division of Nephrology, Clinic of Research in Nephrolithiasis, Evangelic University Hospital and Catholic \\ University of Paraná (PUC - PR), Curitiba, Paraná, Brazil.
}

\begin{abstract}
Purpose: To study the changes in calcium oxalate crystal morphology induced by different levels of supersaturation (SS) in human urine.

Materials and Methods: Twenty-four hours urine samples from 5 normal men were collected. Each specimen was centrifuged and filtered. About $200 \mathrm{~mL}$ of each sample was dialyzed overnight. Aliquots of $2 \mathrm{~mL}$ of urine was then added to a 24-wells tissue culture plate and checked for crystal absence. Calcium oxalate crystals were precipitated from each sample by adding sodium oxalate and calcium chloride in sufficient quantities to induce spontaneous crystallization. Finally, each plate hole was examined with an inverted polarized microscope (X500 magnification). Initial SS of each sample relative to calcium oxalate was calculated using an iterative computer program.

Results: Crystal formation was connecte to relative calcium oxalate (CaOx) SS. At SS of 10, small crystals of similar shape were formed, mainly $\mathrm{CaOx}$ dihydrate morphology. At SS of 30, there was an enormous increase in the number of crystals, that kept the same size. SS greater than 50 produced larger crystals with different shapes and multiple crystalline aggregates. Urine was able to tolerate, i.e., to avoid crystal formation, until SS ratios of approximately 10.

Conclusions: Relative $\mathrm{CaOx}$ SS and the concentration ratio of calcium to oxalate are important determinanting factors of crystal morphology. Non-dialyzable urinary proteins can act as inhibitors and influence the structure of formed crystals. Additional studies from patients with kidney stones are needed in order to establish whether crystal size and habit distribution are different from crystals in normal urine.
\end{abstract}

Key words: urolithiasis; crystallization; calcium oxalate

Int Braz J Urol. 2004; 30: 205-9

\section{INTRODUCTION}

During the process of water conservation, kidneys supersaturate urine (1). Supersaturation (SS) in relation calcium oxalate and phosphate salts is the driving force for crystallization in solutions like urine, which means that it will contain crystals that are formed spontaneously. If inhibitors of crystal formation were not able to act and control their size, the final result will be nephrolithiasis and/or nephrocalcinosis $(2,3)$.
The understanding of crystalluria requires some knowledge of crystal nucleation, growth and aggregation, all of which depend greatly on solution concentration. Both the monohydrate and dihydrate species of calcium oxalate $(\mathrm{CaOx})$ crystals are present in kidney stones (4). It has been proposed that crystalluria may be predictive of a nephrolithogenic tendency (5). Also, crystalluria with oxalate crystal volume measurement is a non-invasive, easily performed investigation, and can give feedback on the efficacy of urolithiasis therapy (6). 
The aim of this study was to examine the changes in calcium oxalate crystal morphology induced by different levels of SS in human urine.

\section{MATERIALS AND METHODS}

Twenty-four hours urine samples from 5 normal subjects was collected without preservative. This urine was screened to exclude bacteria, protein and glucose before being pooled. Each specimen were centrifuged for $15 \mathrm{~min}$ at $8,000 \mathrm{x}$ g and passed through Millipore filters with a pore size of $0.22-\mu \mathrm{m}$ (Millipore Corp., Bedford, Massachusetts). About 200 $\mathrm{mL}$ of each sample was dialyzed for 24 hours against 5 liters of distilled water at a temperature of $4^{\circ} \mathrm{C}$, with 2 changes of water. The dialysis membranes had 3$\mathrm{kd}$ molecular weight cutoff.

Stock solutions of calcium chloride $(2 \mathrm{~mm})$ and sodium oxalate $(0.5,1$ and $4 \mathrm{~mm})$ were used. All solutions were prepared with reagent-grade chemicals, and double-distilled water.

Aliquots of $2 \mathrm{~mL}$ of dialyzed urine was added to a 24-wells tissue culture plate at $37^{\circ} \mathrm{C}$ and checked for crystal absence. After that, calcium oxalate crystals were precipitated from each urine sample by adding $0.5 \mathrm{~mL}$ of sodium oxalate and $0.5 \mathrm{~mL}$ of calcium chloride. Oxalate ion was added as the last component, after mixing the other 2 components. One well had no oxalate added to serve as control.

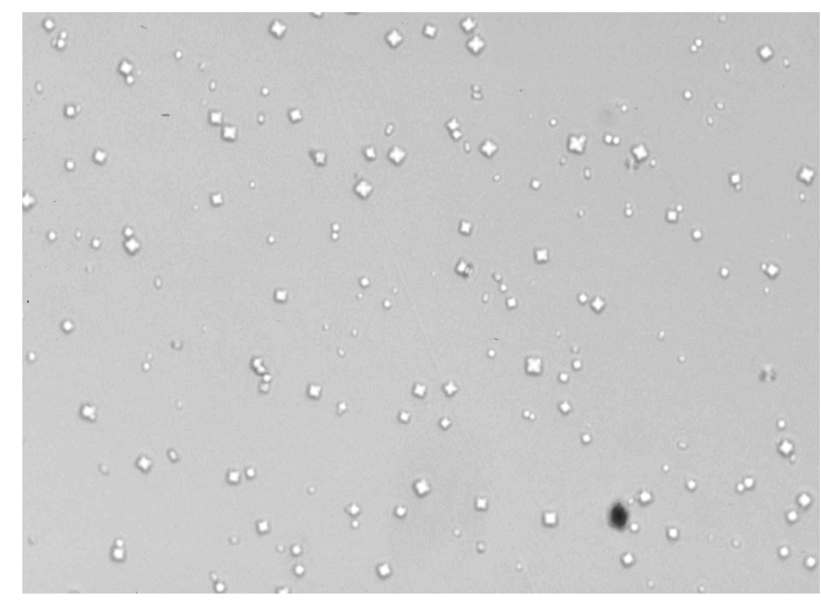

Figure 1 - Calcium oxalate crystals with typical tetragonal bipyramidal habit. (500x-magnification)
The plate was incubated in a shaking water bath at $37^{\circ} \mathrm{C}$ for 1 hour. Finally, the content of each plate well was examined for crystal identification with an inverted polarized microscope (X500 magnification) and optical photomicrographs of any crystals present were taken. The size of individual crystals was estimated using a graduated scale in ocular lens.

The SS of each sample in relation to calcium oxalate at the point of precipitation was calculated by an interactive computer program (Equil 1.3, University of Gainsville, Fl, USA).

\section{RESULTS}

Relative SS increased due to the increase of oxalate concentration. Using dialyzed urine and calcium chloride at a fixed concentration of $2 \mathrm{~mm}$, the addition of $0.5,1$ and $4 \mathrm{~mm}$ sodium oxalate resulted in SS of 10, 30 and 50, respectively. Urine was able to tolerate, i.e., to avoid crystal formation, until SS ratios of approximately 10 .

Crystal formation seems to be related to calcium oxalate SS. At SS of 10, small crystals of similar shape were formed, mainly $\mathrm{CaOx}$ of dihydrate morphology (Figure-1). Their size could be estimate to vary between 15 to $20 \mu \mathrm{m}$.

Using sodium oxalate in $1 \mathrm{~mm}$ to produce a relative SS of 30 caused an enormous increase in the

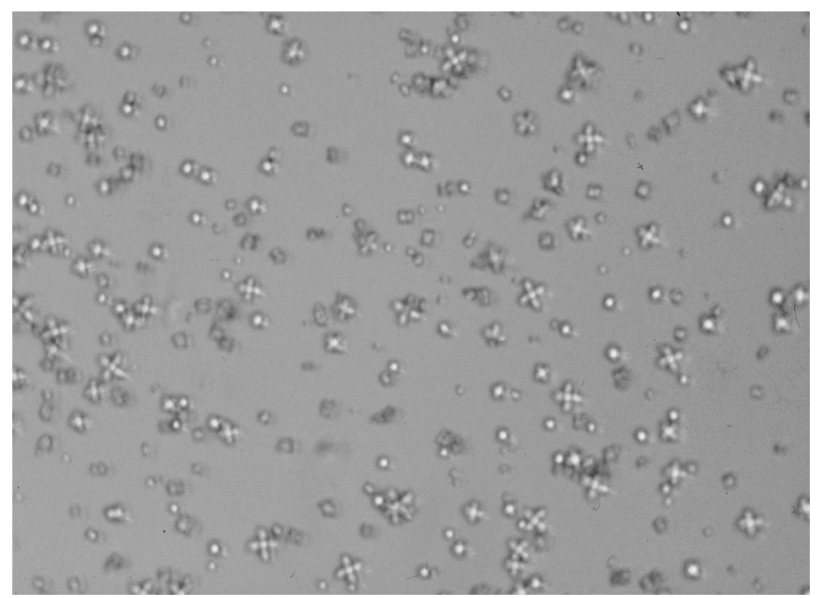

Figure 2 - Same morphology as figure 1 but crystals increased in number, as SS increased. (500x-magnification) 


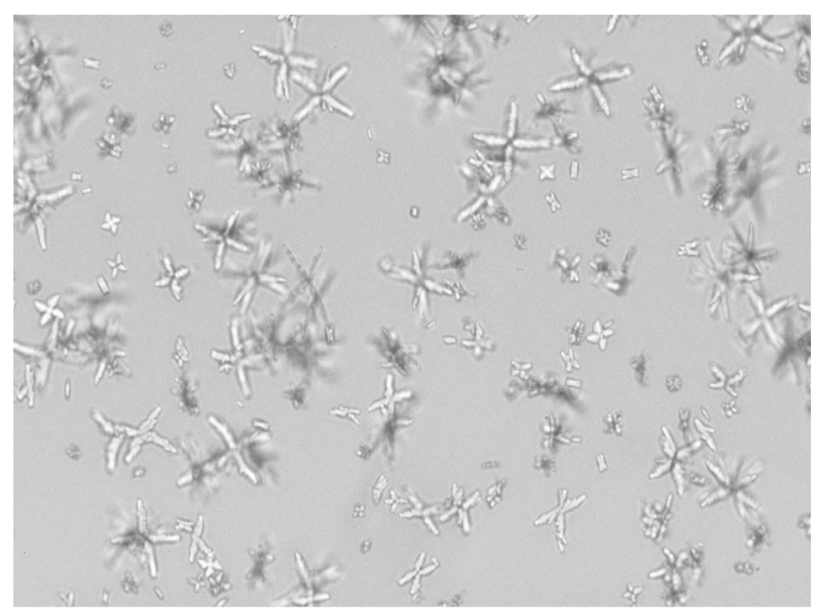

Figure 3 - With high level of SS, the crystals changed, showing $X$-shaped habit and increased diameter. (500x-magnification)

number of crystals, most of then keeping the same size and morphology observed with an SS of 10 (Figure-2). These octahedral crystals also have the characteristic morphology of $\mathrm{CaOx}$ dihydrate crystals.

SS greater than 50 produced larger crystals (Figure-3) with different shapes and multiple crystalline aggregates (Figure-4). Some of these crystals suffered a peptization process and generated fragments of 50 to $100 \mu \mathrm{m}$ of diameter. We should also observe that, when the concentration ratio of calcium to oxalate was kept above one, the crystals formed had a typical $\mathrm{CaOx}$ dihydrate morphology.

\section{DISCUSSION}

Crystals of calcium oxalate are often found in urine (7). Even though crystalluria by itself could be considered as a harmless phenomenon, in some patients it could imply an existing or preexisting urinary SS and an increased risk of nephrolithiasis (8). A pathologic calcification like a Randall's plaque can also be generated by intense deposition of crystals inside the urinary tract (9).

In urine, measured $\mathrm{CaOx} \mathrm{SS}$ rarely exceeds 30. This suggests that nucleation inside the urinary tract is heterogeneous. In this scenario, clusters of crystal-salt ions can be generated by a central nucleus of cell debris, for example. Higher CaOx SS, probably around 80 is apparently necessary to create

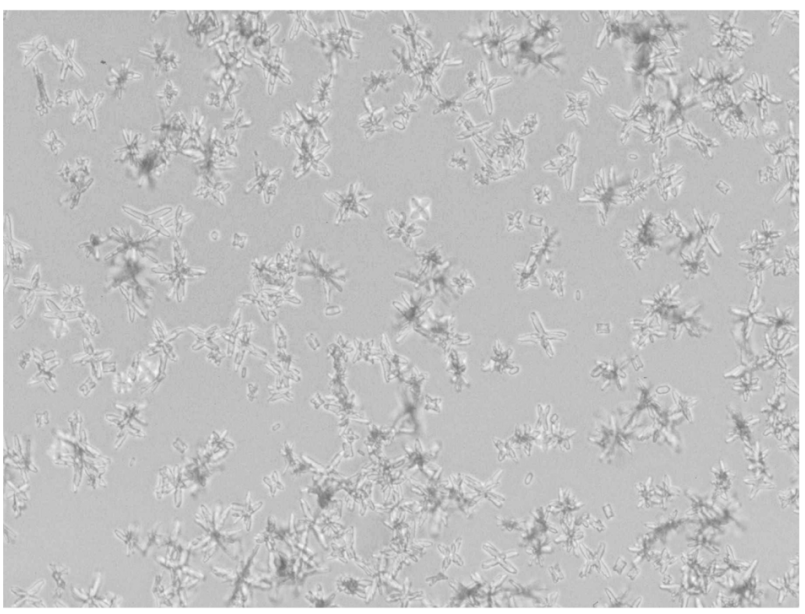

Figure 4-Multiple crystalline aggregates, with increased volume and different habit. (500x-magnification)

homogeneous nucleation (10). This kind of nucleation is characterized by a decrease in the average crystal size caused by intense precipitation and peptization of crystals.

In this work we were able to demonstrate that different urinary $\mathrm{CaOx}$ SS modulates structure and crystalline habit in human urine. Using this model, we could verify that relative SS and the concentration ratio of calcium to oxalate are important factors in the determination of crystal morphology. The urine blocked formation of crystals until $\mathrm{CaOx}$ SS reached 10. This effect is probably due to several non-dialyzable macromolecular inhibitors present in it, like nephrocalcin, glycosaminoglycans, Tamm-Horsfall/uromodulin, and osteopontin for example (2-3,11-12). When the relative SS varied between 10 and 30 , there was an interesting relationship among these inhibitors of crystallization and the physicochemical burden imposed by high concentration of calcium and oxalate. We can attribute the increase of crystal number to SS and the preservation of crystal structure to urinary proteins, as previously demonstrated by Wesson et al. (4). When the $\mathrm{CaOx}$ SS was higher than 50, there was almost no space for inhibitors of crystallization to act and the crystals aggregated and peptized almost immediately.

Very similar conclusions to this study were obtained by Burns \& Finlayson (13). In their work, 
the crystals were examined optically and with X-ray diffraction and their morphology was found to be closely related to relative SS. Nevertheless, they used simple buffer solutions, rather than urine, and even the authors pointed that doubtfully their results could apply to a complex solution as urine.

\section{CONCLUSIONS}

Relative $\mathrm{CaOx} \mathrm{SS}$ and the concentration ratio of calcium to oxalate are important determinants of crystal morphology, mainly in the range of SS of 10 to 30 . Non-dialyzable urinary proteins can act as inhibitors and influence the structure of formed crystals. Additional studies from patients with kidney stones are needed to establish whether crystal size and habit distribution are different from crystals in normal urine.

\section{REFERENCES}

1. Carvalho M, Nakagawa Y: Urinay supersaturation and recurrence in nephrolithiasis. J Bras Urol. 1999; 25: 475-9. [in Portuguese]

2. Carvalho M, Mulinari RA, Nakagawa Y: Role of Tamm-Horsfall protein and uromodulin in calcium oxalate crystallization. Braz J Med Biol Res. 2002; 35: 1165-72.

3. Kurutz JW, Carvalho M, Nakagawa Y: Nephrocalcin isoforms coat crystal surfaces and differentially affect calcium oxalate monohydrate crystal morphology, growth, and aggregation. J Cryst Growth. 2003; 255: 392-402.
4. Wesson JA, Worcester EM, Wiessner JH, Mandel NS, Kleinman JG: Control of calcium oxalate crystal structure and cell adherence by urinary macromolecules. Kidney Int. 1998; 53: 952-7.

5. Rushton HG, Spector M: Effects of magnesium deficiency on intratubular calcium oxalate formation and crystalluria in hyperoxaluric rats. J Urol. 1982; 127: 598-604.

6. Jouvet P, Priqueler L, Gagnadoux MF, Jan D, Beringer A, Lacaille F, et al.: Crystalluria: A clinically useful investigation in children with primary hyperoxaluria post-transplantation. Kidney Int. 1998; 53: 1412-6.

7. Cifuentes Delatte L, Catalina F, Garcia-Vicente J, Esteban B: Electron microscopy and x-ray diffraction of precipitated urinary calcium phosphates. Br J Urol. 1967; 39: 450-5.

8. Gill WB, Ruggiero K, Strauss HB: Crystallization studies in an urothelial lined living test tube (the catheterized female rat bladder). I. Calcium oxalate crystal adhesion to the chemically injured rat bladder. Invest Urol. 1979; 17: 257-61.

9. Evan AP, Lingeman JE, Coe FL, Parks JH, Bledsoe SB, Shao Y, et al.: Randall's plaque of patients with nephrolithiasis begins in basement membranes of thin loops of Henle. J Clin Invest. 2003; 111: 607-16.

10. Finlayson B.: Physicochemical aspects of urolithiasis. Kidney Int 1978; 13: 344-60.

11. Worcester EM. Inhibitors of stone formation. Semin Nephrol. 1996; 16: 474-86.

12. Carvalho M, Lulich JP, Osborne CA, Nakagawa Y.: Role of urinary inhibitors of crystallization in uric acid nephrolithiasis: Dalmatian dog model. Urology 2003; 62: 566-70.

13. Burns JR, Finlayson B.: Changes in calcium oxalate crystal morphology as function of concentration. Invest Urol. 1980; 18: 174-7.
Received: January 23, 2004 Accepted after revision: May 10, 2004

\author{
Correspondence address: \\ Dr. Mauricio Carvalho \\ Kidney Institute, Clinic of Research in Nephrolithiasis \\ Rua Augusto Stelfeld, 2034, \\ Curitiba, Pr, 80730-150, Brazil \\ Fax: + $5541222-6029$ \\ E-mail: carvalho@mais.sul.com.br
}




\section{EDITORIAL COMMENT}

In this manuscript, the authors assess changes in calcium oxalate crystal morphology with various changes in urine supersaturation. Using human urine in an in vitro system, the authors found various changes in crystal morphology as the human urine supersaturation was increased from 10 to greater than 50. The authors conclude that the relative calcium oxalate supersaturation and the concentration ratio of calcium to oxalate are important determinants of crystal morphology. Overall, this is an interesting concept, but one that is not particularly new. Moreover, the authors comment that urinary proteins such as glycosaminoglycans, Tamm-Horsfall proteins and osteopontin may act as inhibitors of calcium oxalate crystallization. However, based on the present findings, they provide no evidence that these proteins were present in the urine samples and their observations with regard to the inhibitory characteristics of these proteins are speculative and based on previous publications.

Dr. Glenn M. Preminger Comprehensive Kidney Stone Center Duke University Medical Center Durham, North Caroline, USA 